\title{
Indicadores geomorfológicos para evaluar la vulnerabilidad por inundación ante el ascenso del nivel del mar debido al cambio climático en la costa de Tabasco y Campeche, México
}

\author{
Rodimiro Ramos-Reyes, Joel Zavala-Gruz, Lilia María Gama-Gampillo, Daniel Pech-Pool, \\ Mario Arturo Ortiz-Pérez
}

\section{Rodimiro Ramos-Reyes}

El Colegio de la Frontera Sur, LAIGE, Carretera Villahermosa-Reforma Km 15.5 S/N. Ranchería Guineo, 2a Sección, C.P. 86280, Villahermosa, Tabasco.

\section{Joel Zavala-Gruz}

zavala_cruz@colpos.mx

Colegio de Postgraduados, Campus Tabasco. Periférico Carlos A. Molina S/N, CP. 86500 , H. Cárdenas, Tabasco, México.

\section{Lilia María Gama-Campillo \\ División de Académica de Ciencias Biológicas. Universidad Juárez Autónoma de Tabasco. Carretera Villahermosa-Cárdenas km. 0.5 $\mathrm{S} / \mathrm{N}$, entronque a Bosques de Saloya. \\ CP. 86150, Villahermosa, Tabasco, México. \\ Daniel Pech-Pool \\ El Colegio de la Frontera Sur, Av. Rancho Polígono 2-A, Ciudad Industrial, CP. 24500, Lerma Campeche, Campeche, México.}

\section{Mario Arturo Ortiz-Pérez}

Instituto de Geografia, UNAM, Investigación Científica, Coyoacán, CP. 04510, Ciudad de México, México.

BOL. SOC. GEOL. MEX. 2016

VOL. 68 NO. 3

P. $581-598$

Manuscrito recibido: Octubre 16, 2015.

Manuscrito corregido recibido: Mayo 8, 2016. Manuscrito aceptado: Mayo 15, 2016.

\section{RESUMEN}

El incremento del nivel del mar puede afectar el $50 \%$ de la población mundial que habita las costas, incluyendo superficies amplias de los estados de Tabasco y Campeche, México. El objetivo del estudio fue identificar la vulnerabilidad de la costa de Tabasco y Campeche a la inundación ante el ascenso del nivel del mar, con base en indicadores geomorfológicos. Con un enfoque geopedológico se zonificaron los paisajes geomorfológicos y relieves, posteriormente se utilizaron como indicadores de vulnerabilidad en una franja costera con anchura media de $20 \mathrm{~km}$. Los indicadores se clasificaron de muy baja a muy extrema vulnerabilidad. Las variables medidas fueron forma del relieve, altura, tipo de roca, proceso geomorfológico y distancia al mar. Se encontraron ocho paisajes geomorfológicos en una superficie de $22322.3 \mathrm{~km}^{2}$. El $67 \%$ del área corresponde a planicies formadas por procesos de acumulación de sedimentos recientes no consolidados. La superficie restante tiene paisajes de terrazas y lomeríos donde prevalecen procesos denudativos y de karsificación. Los paisajes geomorfológicos más vulnerables son planicie costera, planicie baja de inundación lagunar y planicie palustre. Sobresalen por su mayor exposición los relieves de cordones de playa, llanura fluvio-marina, depresión de turba, petenes con turba, llanura salina, delta de marea, dunas costeras y depresión de resurgencias, que cubren el $48 \%$ de la costa. La zona más vulnerable incluye varias ciudades portuarias que involucran 437836 habitantes, así como las reservas ecológicas Laguna de Términos, Los Petenes y Pantanos de Centla.

Palabras clave: costa, incremento del nivel del mar, vulnerabilidad y geomorfología costera.

\section{ABSTRACT}

The rise in sea level may affect $50 \%$ of the world population that lives on the seashores, including vast areas of the states of Tabasco and Campeche, Mexico. The objective of the study was to identify the vulnerability of the coast of Tabasco and Campeche to flooding by sea level rise, based on geomorphologic indicators. With a geopedological approach, geomorphological landscapes and reliefs were differentiated, and used as indicators of vulnerability on a coastal strip with an average width of $20 \mathrm{~km}$. The indicators were classified from very low to very extreme vulnerability. Variables measured were landform, elevation, type of rock, geomorphologic process, and distance from the shore. Eight geomorphologic landscapes were found in a surface of $22322.3 \mathrm{~km}^{2}$. Plains constitute $67 \%$ of the area and were created through a process of accumulation of recent unconsolidated sediments. The remaining area has landscapes of terraces and sets of hills where denudation and karstification processes prevail. The most vulnerable landscapes are the coastal plains, low plains of lagoon flooding, and marsh plains. Standing out for their greater exposure are the beach ridges, fluvial-marine plains, depression peats, salt plains, delta tide, coastal dunes, and slump of resurgences that cover $48 \%$ of the coast. The most vulnerable zone includes various coastal cities that house 437836 habitants, as well as the ecological reserves Laguna de Terminos, Los Petenes and Pantanos de Centla.

Keywords: coast, sea level rise, vulnerability and coastal geomorphology. 


\section{Introducción}

El aumento del nivel del mar es cada vez mayor y pone en peligro a regiones tanto desarrolladas como en vías de desarrollo (Zhang et al., 2004; Nicholls, 2007; Harvey y Nicholls, 2008; Ellison, 2015). Las zonas costeras destacan entre las más vulnerables a la erosión e inundaciones (Bernatchez et al., 2011; Brammer, 2014), por su topografia baja (IPCG, 2012) y mayor densidad de población (Islam et al., 2015), en comparación con el interior de los continentes (Andrade et al., 2004; Marcominii y López, 2010).

La costa es una zona amplia que abarca relieves de litoral, acantilados, terrazas marinas y planicies costeras, están en constante transformación por la acción de las olas, corrientes litorales, mareas, movimientos tectónicos, oscilaciones del nivel del mar, erosión, acumulación fluvial y la actividad humana (Kokot y Chomnalez, 2012; Torresan et al., 2012). Los litorales se pueden dividir en rocosos y no rocosos, erosivos y acumulativos, de acuerdo a la dinámica de los procesos exógenos, tectónicos y el tipo de roca (Ortiz-Pérez et al., 2011). En las costas de México ha aumentado la frecuencia e intensidad de fenómenos climáticos y meteorológicos, provocando, erosión litoral, transformación de ecosistemas, aumento en el nivel promedio del mar e intrusión de agua salina (Magaña et al., 2011). Con frecuencia han sido ocupadas por sus paisajes atractivos (Liquete et al., 2013; Pikelj y Juracic, 2013), resultando entre las más perturbadas del planeta (Islam et al., 2015). Aunque se han implementado algunas infraestructuras para prevenir la erosión, con efectos positivos y negativos (Olivo-Garrido et al., 2012), es recomendable adoptar una mezcla de acciones de adaptación y políticas de mitigación en zonas costeras (Nicholls, 2004), ya que sus características varían en cada país (Farhan y Lim, 2011; Addo, 2013), igual que las variaciones del nivel del mar, como ocurre en el Golfo de México (Zavala-Hidalgo et al., 2011). El conocimiento de la geomorfología costera es fundamental para cuantificar la vulnerabilidad (Thieler y Hammer, 1999; Islam et al., 2015), es- tablecer en forma precisa su evolución ante la elevación del nivel del mar y plantear alternativas de protección (CEPAL, 2012; Torresan et al., 2012). La geomorfología proporciona información valiosa para la toma de decisiones en la evaluación de ordenamientos territoriales, protección, infraestructura costera y políticas públicas (Farhan y Lim, 2011; Pikelj y Juracic, 2013), buscando alternativas de protección (CEPAL, 2012; Torresan et al., 2012) para minimizar los escenarios de vulnerabilidad (IPCG, 2012).

Los paisajes geomorfológicos costeros son la base fundamental para cuantificar la vulnerabilidad de los ambientes (Torresan et al., 2012; Addo, 2013), utilizando indicadores como la erosión, facilitando la cuantificación de impactos y estrategias implementadas para reducirla y mitigarla (Palacio-Aponte, 2010). Ayudan a visualizar cambios e identificar aspectos que requieren mayor atención (Buch y Turcios, 2003), focalizar las zonas con muy baja a muy alta vulnerabilidad (Thieler y Hammer, 1999; Ojeda et al., 2009; Marcominii y López, 2010), y brindar atención a sitios que resulten focos rojos y prevenir posibles impactos. El tipo de relieve es uno de los indicadores geomorfológicos que contribuye a estructurar el nivel de vulnerabilidad (Buch y Turcios, 2003) y es de utilidad como antecedente para la elaboración de instrumentos de regulación del territorio (Pikelj y Juracic, 2013). En Europa los estudios de vulnerabilidad costera son usados para coadyuvar a la planificación espacial terrestre y marina (Liquete et al., 2013).

En este estudio, se zonificaron las geoformas aplicando el enfoque geopedológico (Zinck, 2012), y se analizan variables geomorfológicas como indicadoras para conocer la vulnerabilidad de la zona costera de Tabasco y Campeche ante el cambio climático. El enfoque geopedológico es un sistema de clasificación jerárquico fácilmente reconocible, que auxilia en la delimitación de unidades en una regionalización natural del terreno, en la cual los aspectos morfológico y edáfico tienen relevancia significativa. Los niveles de geoformas aplicables a estudios regionales y locales son: paisaje geomor- 
fológico, relieve/modelado y litología/facies. El paisaje geomorfológico consiste en una gran porción del terreno caracterizada por una repetición de tipos de relieve/modelado similares (planicie, valle, lomerío); las unidades se presentan a escala 1:250000. El relieve/modelado es un tipo de relieve originado por una combinación de topografía y estructura geológica, y por las condiciones morfoclimáticas (mesa, loma, depresión, llanura de inundación, delta, polje); aplica a estudios a escala 1:50000. La litología/facies se refiere a la naturaleza petrográfica de la roca dura (caliza, basalto) y a las facies de las formaciones superficiales (lacustre, aluvial, costero); las unidades se presentan a escala 1:25000. El enfoque geopedológico tiene aplicación en estudios de recursos naturales, zonificación de peligros y vulnerabilidad, evaluación de tierras y ordenamiento territorial (Bocco et al., 1999; Bocco et al., 2010; Zinck, 2012).

\section{2. Área de trabajo, métodos y materiales estudiados}

\subsection{DESCRIPCIONES DEL ÁREA DE TRABAJO}

La zona costera del estado de Tabasco y Campeche se localiza entre los $17^{\circ} 15^{\prime}$ y $20^{\circ} 51^{\prime}$ de latitud Norte, y los $89^{\circ} 06^{\prime}$ y $94^{\circ} 17^{\prime}$ de longitud Oeste, cubriendo una superficie de $22322.3 \mathrm{~km}^{2}$ en la costa sur del Golfo de México (Figura 1). Esta porción costera se reporta como Litoral Sur-Oriental (Tabasco hasta Laguna de Términos en Campeche), Litoral Occidental y Norte de la Península de Yucatán (de Isla Aguada en Campeche hasta Yucatán) (De la Lanza et al., 2013).

La delimitación de la zona de estudio consideró dos criterios: el primero fue una franja de $20 \mathrm{~km}$ de la zona costera a partir del litoral, y el segundo integró las planicies palustres con anchura mayor a $20 \mathrm{~km}$, más una franja interior de $5 \mathrm{~km}$ (Figura $1)$.

\subsection{METODOS}

Se revisó literatura para seleccionar los indicadores de vulnerabilidad costera relacionados con el relieve y se adaptaron las clasificaciones propuestas por Thieler y Hammer (1999) y Ojeda et al. (2009), con modificaciones propias acorde a las características específicas de la costa de Tabasco y Campeche (Tabla 1).

Se diferenciaron los niveles de geoformas denominados paisaje geomorfológico y relieve/modelado con base en el enfoque geopedológico (Zinck, 2012); en la unidad relieve/modelado se conjuntó información de litología/facies como lo proponen Bocco et al. (1999).

\subsection{CARTOGRAFÍA DE PAISAJES GEOMORFOLÓGICOS Y RELIEVE/MODELADO}

Los linderos de paisajes geomorfológicos escala 1:250000 se basaron en la cartografía generada por Ortiz-Pérez et al. (2005), Palacio-Aponte et al. (2005), Jiménez (2014) y Bautista et al. (2015), y los de relieve/modelado escala 1:50000 se mejoraron a partir de levantamientos geomorfológicos y geopedológicos en la región (Domínguez et al., 201 1; Palma-López et al., 2012; Zavala et al., 2012; Jiménez, 2014). La cartografía geomorfológica se elaboró mediante la integración de las bases utilizando los sistemas de información geográfica ARC GIS y QGIS.

La caracterización de los paisajes y relieves se basó en información morfométrica sobre: a) forma y procesos gemorfológicos, sintetizados de estudios geomorfológicos y geopedológicos en la región (Ortiz-Pérez et al., 2005; Palacio-Aponte et al., 2005; Hernández-Santana et al., 2008; Domínguez et al., 2011 ; Ortiz-Pérez et al., 2011; Palma-López et al., 2012; Zavala et al., 2012; Jiménez, 2014; Bautista et al., 2015; Zavala-Cruz et al., 2016); b) altura sobre el nivel del mar (asnm) y pendiente (\%), se obtuvieron de mapas topográficos de INEGI, fuentes bibliográficas y verificación de campo con GPS y brújula Brunton; c) tipo de roca y edad, se recopi- 


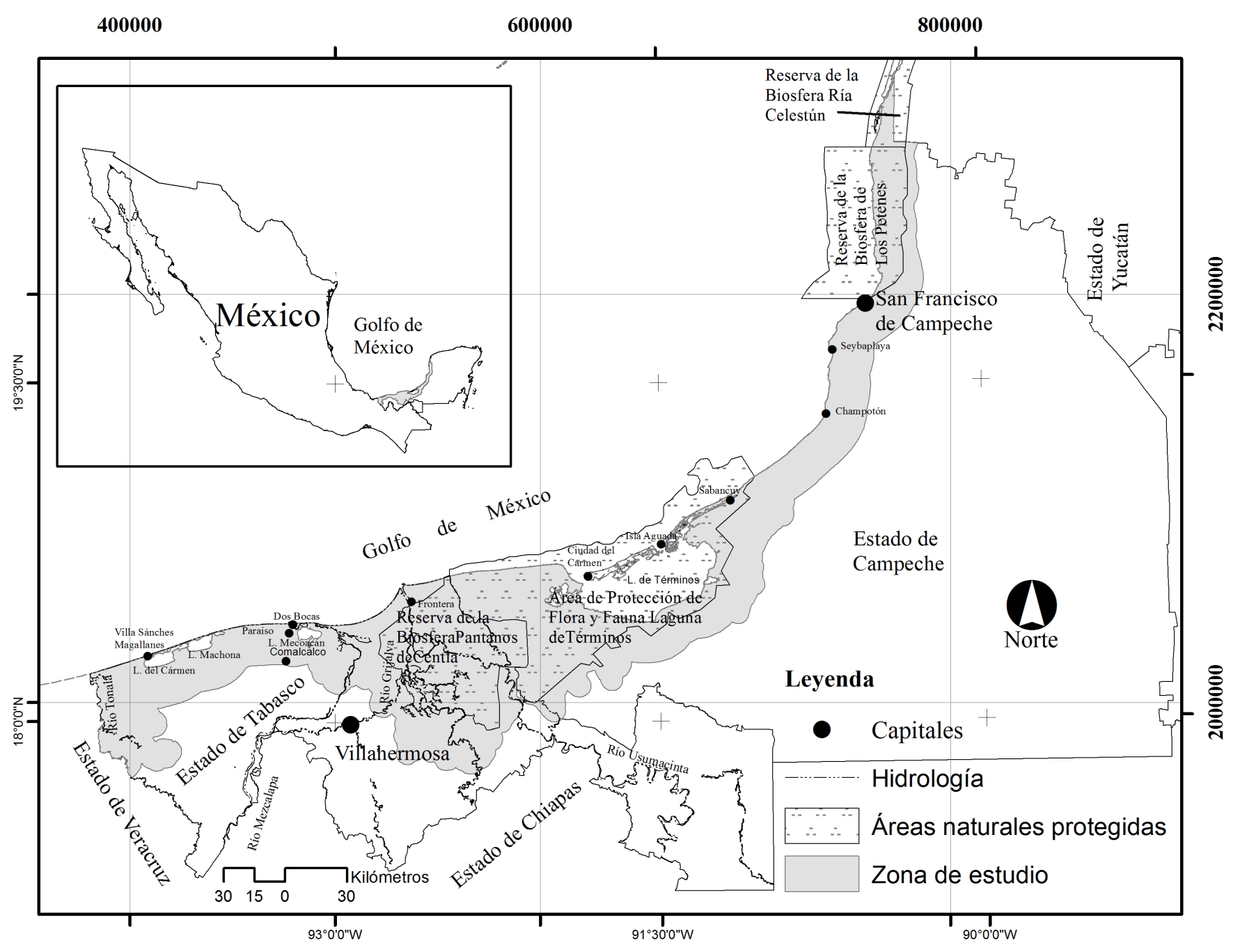

Figura 1 Localización del área de estudio en los estados de Tabasco y Campeche, México.

ló de cartografía geológico-minera Esc. 1:250000 (Aguilera et al., 2004; Cardoso et al., 2005; Miranda et al., 2005) y fuentes bibliográficas (Ortiz-Pérez et al., 2005; Bautista et al., 2015).

\subsection{ANÁLISIS DE LA VULNERABILIDAD COSTERA}

En esta etapa se aplicaron los indicadores de vulnerabilidad geomorfológica (Tabla 1) para conocer la vulnerabilidad de la zona costera de Tabasco y Campeche ante la inundación por el ascenso del nivel del mar debido al cambio climático, considerando un incremento del nivel del mar que puede variar de $59 \mathrm{~cm}$ (IPCC, 2007) a más de un metro para el año 2100, asociado a un deshielo glaciar más rápido por un mayor incremento de temperatura (Rahmstorf, 2012). El análisis de la vulnerabilidad geomorfológica se basó en los mapas de paisajes geomorfológicos, relieve/modelado y en la información morfométrica generada para la zona de estudio. El mapa de vulnerabilidad costera se diseñó mediante interpolación y análisis geográfico con un software especializado, utilizando versiones actualizadas de información geográfica de ARG GIS, ERDAS IMAGINE y QGIS. 
Tabla 1. Clases de vulnerabilidad a la inundación ante el ascenso del nivel del mar asociada a tipos de relieve/modelado costero con base en Thieler y Hammer (1999) y Ojeda et al. (2009), modificadas en el presente estudio.

\begin{tabular}{|c|c|c|}
\hline Clase & Valor & Indicador geomorfológico \\
\hline Muy bajo & 1 & $\begin{array}{l}\text { Relieve modelado positivo de terrazas onduladas y lomeríos, topografía elevada ( } 2 \text { a } 95 \mathrm{msnm}) \text {, } \\
\text { pendiente suave a fuerte }(2-40 \%) \text {, roca consolidada a moderadamente consolidada, expuesta a } \\
\text { procesos exógenos climáticos, contiguo o alejado de la línea de costa. }\end{array}$ \\
\hline Bajo & 2 & $\begin{array}{l}\text { Relieve modelado de planicies y terrazas ligeramente onduladas, topografía elevada ( } 2 \text { a } 30 \mathrm{msnm}) \text {, } \\
\text { pendiente suave (1-6 \%), roca consolidada a moderadamente consolidada, expuesta a procesos } \\
\text { exógenos climáticos, alejado de la línea de costa. }\end{array}$ \\
\hline Medio & 3 & $\begin{array}{l}\text { Relieve modelado en planicies, terrazas y valles acumulativos, con topografía baja a intermedia ( } 2 \text { a } \\
15 \text { msnm), pendiente plana ( } 1-3 \% \text { ), roca no consolidada, procesos acumulativos de sedimentos } \\
\text { aluviales y deluviales, alejado de la línea de costa. }\end{array}$ \\
\hline Alto & 4 & $\begin{array}{l}\text { Relieve modelado en planicies, depresiones y formas cóncavas, con topografía baja ( } 1 \text { a } 7 \mathrm{msnm}) \text { y } \\
\text { pendiente plana ( } 1-2 \%) \text {, sedimentos no consolidados, procesos acumulativos de sedimentos aluviales } \\
\text { y palustres, no contiguo a la línea de costa. }\end{array}$ \\
\hline Muy alto & 5 & $\begin{array}{l}\text { Relieve modelado en planicies y depresiones, con topografía baja ( } 1 \text { a } 7 \mathrm{msnm}) \text { y pendiente plana (1-3 } \\
\% \text { ), sedimentos no consolidados, expuesto a erosión y acumulación por procesos litorales, eólicos, } \\
\text { palustres y fluviales, contiguo a la línea de costa y en conexión con superficies amplias hacia al } \\
\text { interior de la zona costera. }\end{array}$ \\
\hline Muy extremo & 6 & $\begin{array}{l}\text { Relieve modelado en planicies y depresiones, con topografía muy baja ( } 0 \text { a } 1 \mathrm{msnm}) \text { y pendiente plana } \\
(<1 \%) \text {, sedimentos no consolidados, expuesto a erosión y acumulación por procesos litorales, } \\
\text { fluviales y palustres, contiguo a la línea de costa y en conexión con el mar. }\end{array}$ \\
\hline
\end{tabular}

\section{Resultados}

\subsection{PAISAJES GEOMORFOLÓGICOS Y RELIEVE/ MODELADO}

La costa de Tabasco y Campeche tiene ocho paisajes geomorfológicos (Figura 2), destacan por su extensión las planicies palustre $(26 \%)$ y fluviodeltaica $(19 \%$ ). El $80 \%$ de la superficie de los paisajes está formada por planicies sobre sedimentos no consolidados, acumulados por procesos fluviales, palustres, eólicos y litorales, de edad Cuaternario Holoceno; su altura varía de 0 a 8 msnm. El $20 \%$ de la región corresponde a paisajes de terrazas y lomeríos, modelados por procesos de erosión, denudación y karsificación, con basamento de rocas sedimentarias detríticas, calizas y margas del Terciario Eoceno al Cuaternario Pleistoceno; la altura varía de 1 a 95 msnm.

En la planicie costera prevalecen materiales arenosos acumulados por corrientes litorales, tiene alturas menores a $7 \mathrm{msnm}$ y pendiente inferior a
$3 \%$. Su mayor anchura (7 a $30 \mathrm{~km})$ se ubica a ambos lados de la desembocadura del Río Usumacinta, en Tabasco y Campeche, indicando la mayor acumulación de sedimentos que favorece el desarrollo de la costa hacia el mar. Una planicie costera de anchura media (5 a $14 \mathrm{~km}$ ) se sitúa entre la laguna de Términos y Champotón, Campeche, y en la desembocadura del Río Tonalá. En ambas costas prevalecen relieves de cordones de playa arenosos paralelos a la costa, tanto altos bien drenados, como bajos sujetos a inundación, estos pueden presentar capas de turba superficial (Figuras 2 y 3); indican procesos acumulativos, y solo se truncan en la desembocadura del río San Pedro y San Pablo debido al retroceso local de la costa. La planicie costera de menor anchura $(0.1$ a $4 \mathrm{~km}$ ) se sitúa entre las desembocaduras de los ríos González y Tonalá, en Tabasco, donde se alternan cordones de playa y dunas costeras (Figuras 2 y 3) paralelos a la costa, indicando procesos de acumulación y erosión; en tramos discontinuos, en la época de nortes, tormentas y ciclones, se forman bermas de tormenta por erosión litoral, sien- 


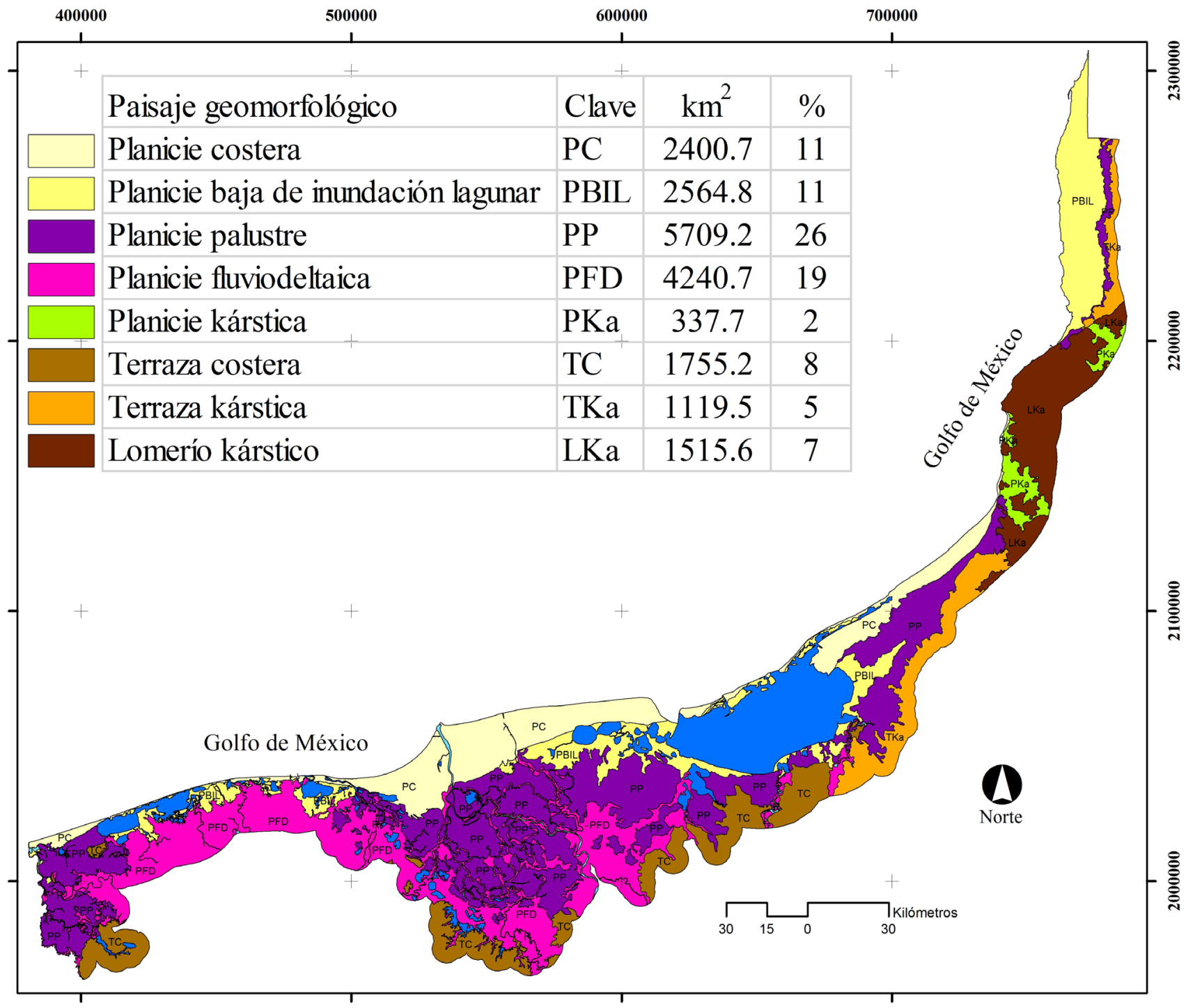

Figura 2 Paisajes geomorfológicos de la costa de Tabasco y Campeche, México.

do más evidentes en un tramo de $50 \mathrm{~km}$ entre las bocas de Tupilco y Sánchez Magallanes, donde la costa tiene menos de $300 \mathrm{~m}$ de ancho (Figuras 2 y 3). Esta planicie se interrumpe al norte de la ciudad de Campeche. La ausencia o escasa anchura de la planicie costera, y las formas erosivas, indican baja intensidad de acumulación de sedimentos marinos.

La planicie baja de inundación lagunar es una franja cóncava situada entre los paisajes de planicie costera, fluviodeltaica y palustre, alrededor de lagunas costeras conectadas con el Golfo de Mé- xico a través de bocas o esteros, por su escasa altura y pendiente (menor a $2 \mathrm{msnm}$ y $1 \%$ ) funciona como nivel de base de corrientes fluviales y de marea, y permanece inundada con agua salobre la mayor parte del año. El sustrato es de sedimentos palustres, marinos y fluviales de textura fina a media en llanuras fluvio-marinas, arenosa en cordones de playa inundados, con capas de turba en depresiones del suroeste y noreste de la laguna de Términos en Campeche, y turba sobre sedimentos calcáreos en llanuras salinas y petenes al norte de Campeche (Figuras 2 y 3 ). 


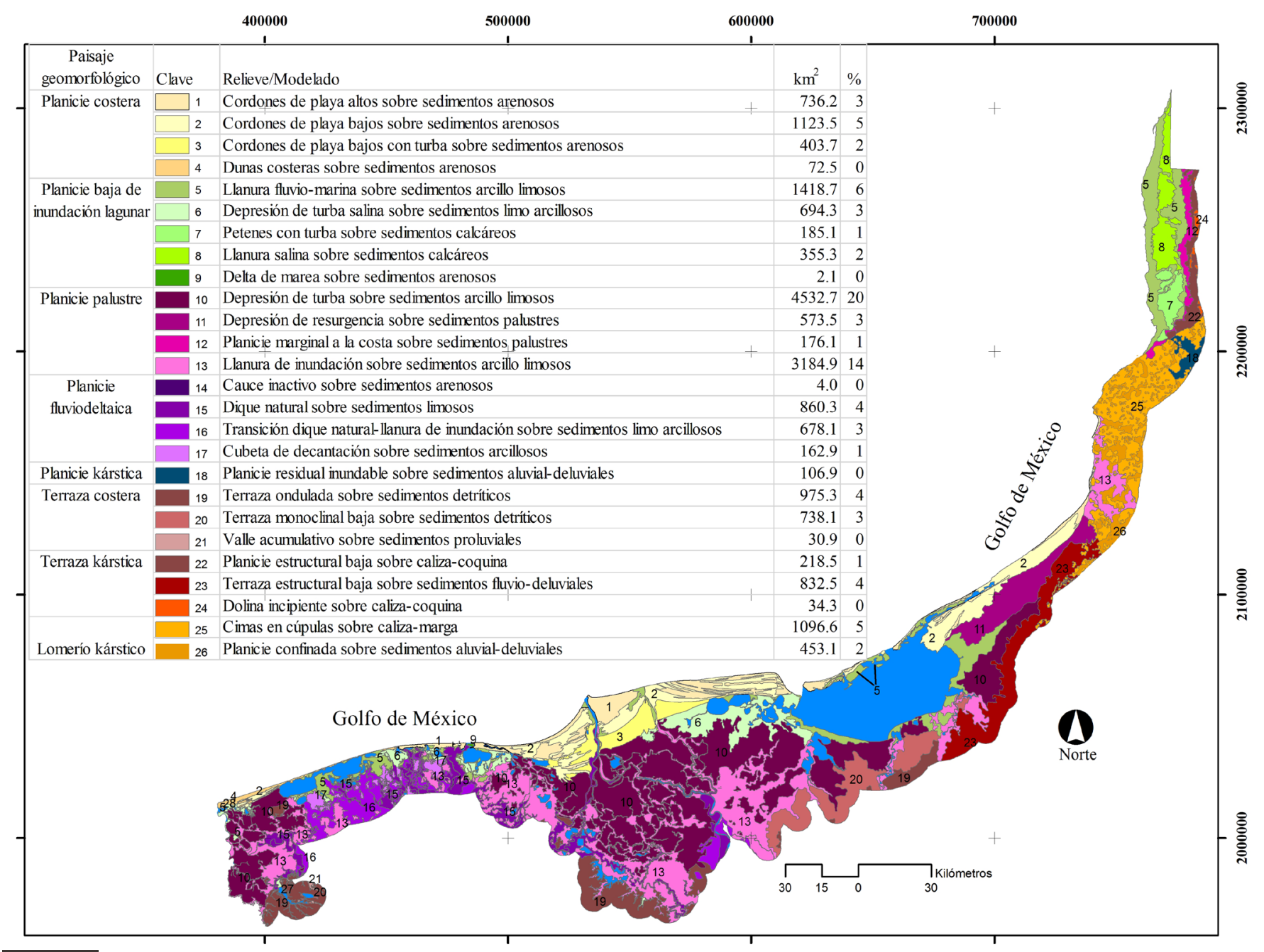

Figura 3 Relieve/modelado de la costa de Tabasco y Campeche, México.

La planicie palustre consiste de amplias depresiones inundables, situadas entre planicies de cordones de playa, de inundación lagunar, fluviodeltaica y terrazas. Capas de turba, con promedio de $1 \mathrm{~m}$ de espesor, yacen sobre sedimentos aluviales; su altura varía de 1 a 3 msnm y la pendiente es menor a $1 \%$; la ubicación en zonas topográficas muy bajas favorece las inundaciones con agua dulce durante 10 meses. Al noreste de la Laguna de Términos, los sedimentos calcáreos acumulados por resurgencias de agua subyacen a capas de turba. La mayor superficie se ubica en la reserva Pantanos de Centla, en el delta del Río Usumacinta, caracterizada por numerosos ríos con llanuras de inundación de escasa anchura (Figuras 2 y 3 ).
La planicie fluviodeltaica es una superficie plana a cóncava, ubicada al sur de las planicies de inundación lagunar y palustre, en los deltas de los ríos Mezcalapa y Usumacinta; prevalecen sedimentos aluviales, su altura y pendiente varían de 1 a 15 msnm y menor a $2 \%$, respectivamente. Los cauces de los ríos se sobreelevan en el plano fluvial, y en sentido perpendicular a estos se desarrollan diques naturales bien drenados, con sedimentos limosos a arenosos depositados durante las inundaciones extraordinarias; en zonas posteriores a los diques, se ubican amplias llanuras de inundación sobre sedimentos arcillo limosos acumulados por avenidas de aguas tranquilas; las cubetas de decantación y lagunas de agua dulce ocupan de- 
presiones situadas 3 a $6 \mathrm{~m}$ abajo de los diques naturales (Figuras 2 y 3 ), las inundaciones prevalecen casi todo el año.

La planicie kárstica es una superficie plana, con sedimentos aluviales y deluviales arcillosos del Holoceno, se sitúa entre 2 y $10 \mathrm{msnm}$, en pendientes menores a $2 \%$, rodeadas de lomeríos kársticos, en la planicie de inundación del río Champotón y el Valle de Edzná, en el estado de Campeche (Figuras 2 y 3$)$.

Terrazas costeras corresponden a superficies ligeramente disectadas, con sedimentos detríticos de areniscas, conglomerado, lutitas, arena y limo, su altura y pendiente varían de 2 a $30 \mathrm{msnm}$ y de 1 a $10 \%$. Prevalecen geoformas de terrazas ligeramente onduladas modeladas por denudación y erosión, planicies monoclinales inactivas y valles erosivo-acumulativos (Figuras 2 y 3 ).

Terraza kárstica es una superficie ligeramente ondulada asociada mayormente a terrazas estructurales bajas (Figuras 2 y 3), con sedimentos aluvial-deluviales, derivados de lomeríos kársticos; algunas planicies estructurales sobre caliza-coquina se ubican al noreste de Campeche, junto a superficies de dolinas incipientes. La altura y pendiente varía de 2 a 30 msnm y 1 a $6 \%$.

Lomerío kárstico consiste de lomas en cúpulas sobre caliza-marga, originadas por procesos tectónicos, denudativos y karsificación; entre las lomas se localizan varias planicies confinadas asociadas a dolinas y poljes (Figuras 2 y 3 ), tienen fondo plano con sedimentos eluvial-deluvial. La altura y pendiente varían de 1 a 95 msnm y 2 a $40 \%$, respectivamente; se localiza al sur de la ciudad de Campeche.

\subsection{VULNERABILIDAD GEOMORFOLÓGICA DE LA COSTA DE TABASCO Y CAMPECHE ANTE EL CAMBIO CLIMÁTICO}

La zona costera de Tabasco y Campeche presenta muy extrema vulnerabilidad geomorfológica por inundación ante el posible ascenso del nivel del mar debido al cambio climático (13\%), sobresaliendo el estado de Campeche. Coincide con relieves de los paisajes planicie baja de inundación lagunar y costera, situados a menos de $1 \mathrm{msnm}$, en conexión con el Golfo de México, tienen sedimentos no consolidados y amplias superficies con capas de turba suprayacentes. El $32 \%$ de la zona costera presenta muy alta vulnerabilidad ante el cambio climático, agrupa extensas depresiones de turba del paisaje planicie palustre, contiguas a la planicie baja de inundación lagunar, y la mayoría de las geoformas de la planicie costera, ubicadas en posición frontal a los procesos litorales; prevalecen superficies con altura menor a $3 \mathrm{msnm}$, sobre sedimentos no consolidados. La zona de alta vulnerabilidad geomorfológica $(16 \%)$ concuerda con llanuras de inundación y cubetas de decantación sobre sedimentos arcillo limosos de las planicies palustre y fluviodeltaica, adyacentes a paisajes de planicie costera e inundación lagunar; la altura es escasa (1 a $7 \mathrm{msnm}$ ) y se ubica relativamente alejada de la línea de costa. La superficie de media vulnerabilidad $(13 \%)$ corresponde a diques naturales y de transición diques naturales-llanura de inundación del paisaje planicie fluviodeltaica, y a llanuras aluviales, deluviales y proluviales de los paisajes planicie kárstica, terrazas y lomerío kárstico; la altura es mayor a 2 msnm y no está expuesta directamente a procesos litorales. La zona de baja vulnerabilidad ( $5 \%$ ) se sitúa en el paisaje de planicie kárstica, sobre rocas calcáreas consolidadas, en alturas mayores a $2 \mathrm{msnm}$, alejada de la línea de costa. El área de muy baja vulnerabilidad (9\%), concuerda con terrazas onduladas y lomeríos con cimas en cúpulas sobre sedimentos moderadamente consolidados y consolidados, en los paisajes terraza costera y lomerío kárstico; casi el total de la superficie supera 2 msnm y está alejada de la línea de costa (Tabla 2 y Figura 4).

\section{Discusión}

\subsection{PAISAJES GEOMORFOLÓGICOS EN ZONAS COSTERAS DE TABASCO Y CAMPECHE, MÉXICO}

El $67 \%$ de la superficie de la zona costera de Tabasco y Campeche tiene paisajes geomorfológicos integrados por relieves planos a cóncavos con esca- 
Tabla 2. Relieve/modelado indicador de vulnerabilidad geomorfológica en la zona costera de Tabasco y Campeche, México.

\begin{tabular}{|c|c|c|c|c|c|c|c|c|c|}
\hline \multirow{2}{*}{ 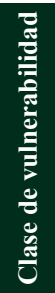 } & \multirow{2}{*}{ 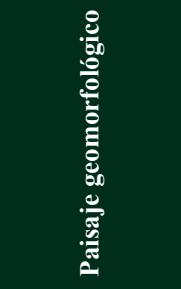 } & \multicolumn{6}{|c|}{ Indicadores geomorfológicos de vulnerabilidad costera } & \multicolumn{2}{|c|}{ Superficie } \\
\hline & & Relieve/modelado & 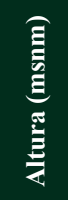 & 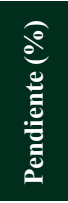 & Tipo de roca & 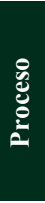 & 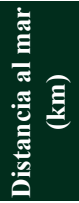 & $\mathbf{k m}^{2}$ & $\%$ \\
\hline 1 & $\begin{array}{l}\mathrm{TC}, \\
\mathrm{LK}\end{array}$ & Terraza ondulada, cimas en cúpulas & $2-95$ & $2-40$ & $\begin{array}{l}\text { Sedimentos detríticos moderadamente } \\
\text { consolidados del Terciario Mioceno al } \\
\text { Cuaternario Pleistoceno, y calizas y } \\
\text { margas consolidadas del Terciario Eoceno }\end{array}$ & $\begin{array}{l}\mathrm{E}, \\
\mathrm{K}\end{array}$ & $0-92$ & 2072 & 9 \\
\hline 2 & TKa & $\begin{array}{l}\text { Planicie estructural baja, terraza estructural } \\
\text { baja, dolina incipiente }\end{array}$ & $2-30$ & $1-6$ & $\begin{array}{l}\text { Caliza, marga y coquina consolidadas del } \\
\text { Terciario Eoceno-Mioceno-Plioceno }\end{array}$ & $\mathrm{K}$ & $8-55$ & 1085.4 & 5 \\
\hline 3 & $\begin{array}{c}\text { PFD, PKa, TC, } \\
\text { LK }\end{array}$ & $\begin{array}{l}\text { Dique natural, transición de dique natural- } \\
\text { llanura de inundación, planicie residual } \\
\text { inundable, terraza monoclinal baja, valle } \\
\text { acumulativo, planicie confinada }\end{array}$ & $2-15$ & $1-3$ & $\begin{array}{l}\text { Sedimentos aluviales y deluviales no } \\
\text { consolidados del Cuaternario Holoceno }\end{array}$ & A & $2-45$ & 2867.4 & 13 \\
\hline 4 & PP, PFD & $\begin{array}{l}\text { Planicie marginal a la costa, llanura de } \\
\text { inundación, cauce inactivo, cubeta de } \\
\text { decantación }\end{array}$ & $1-7$ & $1-2$ & $\begin{array}{l}\text { Sedimentos aluviales y palustres no } \\
\text { consolidados del Cuaternario Holoceno }\end{array}$ & A & $2-90$ & 3628.8 & 16 \\
\hline 5 & $\begin{array}{l}\text { PC, } \\
\text { PP }\end{array}$ & $\begin{array}{l}\text { Cordones de playa altos y bajos, dunas } \\
\text { costeras, depresión de turba, depresión de } \\
\text { resurgencias }\end{array}$ & $1-7$ & $1-3$ & $\begin{array}{l}\text { Sedimentos litorales, eólicos, palustres y } \\
\text { aluviales no consolidados del Cuaternario } \\
\text { Holoceno }\end{array}$ & A & $0-70$ & 7038.4 & 32 \\
\hline 6 & PC, PBIL & $\begin{array}{l}\text { Cordones de playa bajos con turba, llanura } \\
\text { fluvio-marina, depresión de turba salina, } \\
\text { petenes con turba, llanura salina, delta de } \\
\text { marea }\end{array}$ & $0-1$ & $<1$ & $\begin{array}{l}\text { Sedimentos litorales, eólicos, palustres y } \\
\text { aluviales no consolidados del Cuaternario } \\
\text { Holoceno }\end{array}$ & $\begin{array}{l}\text { A, } \\
\text { E }\end{array}$ & $0-35$ & 2958.3 & 13 \\
\hline & ríos & & & & & & & 2678.8 & 12 \\
\hline
\end{tabular}

Paisaje geomorfológico: PC Planicie costera, PBIL Planicie baja de inundación lagunar, PP Planicie palustre, PFD Planicie fluviodeltaica, PKa Planicie kárstica, TC Terraza costera, TKa Terraza kárstica, LK Lomerío kárstico. Proceso: A Acumulación, D Denudación, E Erosión, K Karsificación.

sa altura y pendiente, donde prevalecen sedimentos no consolidados fluviales, litorales, palustres y lagunares acumulados en el Cuaternario Holoceno (Figura 3); estas geoformas concuerdan con las reportadas en zonas costeras de topografía plana (Ortiz-Pérez et al., 2005; Geissert-Kientz y Enríquez-Fernández, 2011; IPCG, 2012; Addo, 2013; Bautista et al., 2015; Zavala-Cruz et al., 2016).

El paisaje de planicie costera funciona como barrera natural de contención (Olivo-Garrido et al., 2012; Liquete et al., 2013; Pikelj y Juracic, 2013) y protección de los paisajes geomorfológicos interiores contra la intrusión salina, especialmente las planicies baja de inundación lagunar y palustre, como se ha verificado en otras zonas costeras (Andréfouët et al., 2015; Islam et al., 2015). Sobresale la dinámica de los procesos geomorfológicos de la planicie costera, por un lado la amplitud de los bordos de playa indican progradación en el delta del Río Grijalva, en la desembocadura del Río Usumacinta (Figura 3), coincidiendo con tasas positivas de crecimiento de la costa registradas por Ortiz-Pérez et al. (2011); y por el otro, la reducida anchura de los bordos de playa y dunas con recurrentes tramos en proceso de erosión ubicados en zonas alejadas de las desembocaduras de los ríos (Figura 3), lo que provoca pérdida de carreteras y reducción de playas, como se ha documentado en otros estudios (Ortiz-Pérez et al., 201 1; Torres-Rodríguez et al., 2011; Kokot y Chomnalez, 2012; Sheik y Chandrasekar, 2013; Brammer, 2014). La erosión se acentúa en el puerto de Sánchez Maga- 


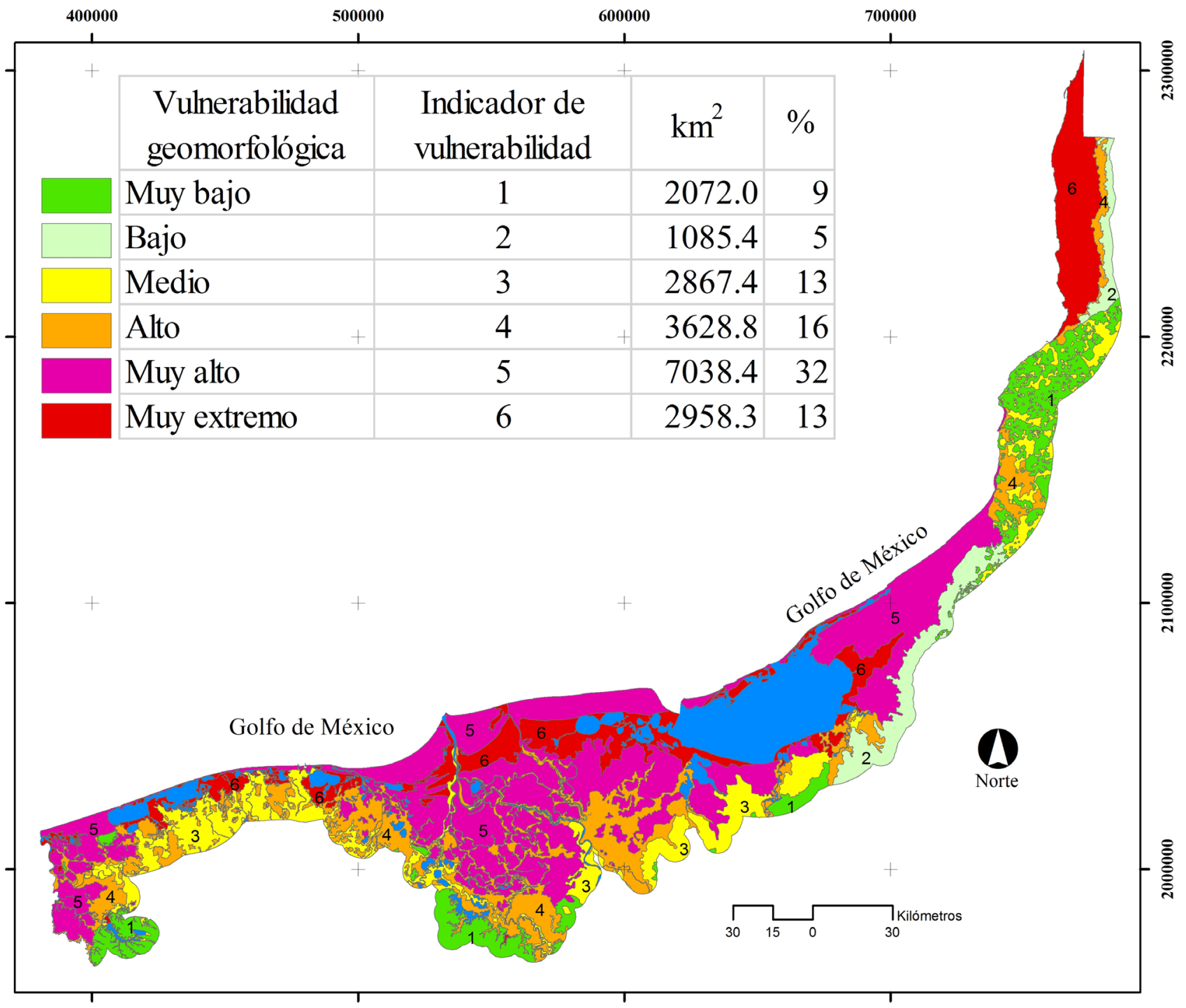

Figura 4 Vulnerabilidad geomorfológica de la costa de Tabasco y Campeche, México.

llanes, Tabasco, y la desembocadura del río San Pedro y San Pablo con tasas de pérdida de costa de -3 a -9 m/año (Hernández-Santana et al., 2008); en el puerto citado, la erosión por acción del oleaje ha destruido viviendas, similar a lo registrado en otras costas erosivas (Bernatchez et al., 2011; Kokot y Chomnalez, 2012; Brammer, 2014; Islam et al., 2015). El retroceso de sectores de la costa en los deltas de Tabasco y Campeche se explica por la disminución de la actividad fluvial (Ortiz-Pérez y De la Lanza-Espino, 2006; Hernández-Santana et al., 2008), y además por hundimientos que pro- vocan un efecto de elevación del mar e incremento en las inundaciones, erosión de la línea de costa y salinización (Ortiz-Pérez y De la Lanza-Espino, 2006), similar a lo reportado para otros litorales (Nicholls y Cazenave, 2010; Brammer, 2014; Ellison, 2015; Islam et al., 2015).

El paisaje geomorfológico de planicie baja de inundación lagunar (Figura 3) está expuesto a impactos severos por aumento del nivel del mar (Flores-Verdugo et al., 2011), seguido de las depresiones de turba de la planicie palustre, así como las cubetas de decantación y las llanuras de inundación de la 
planicie fluviodeltaica, contiguas a las planicies baja de inundación lagunar y palustre (Figura 3), cuya forma cóncava a plana, topografía muy baja y posición cercana a la línea de costa, pueden favorecer la intrusión e inundación con agua marina; los ecosistemas inundables de estas geoformas estarán expuestos a la desaparición por elevación del nivel del mar, como se ha pronosticado para zonas costeras de África (Addo, 2013; Ellison, 2015), el norte del Adriánico, Italia (Torresan et al., 2012), y otros humedales similares (Olivo-Garrido et al., 2012). Varios relieves pueden funcionar como vía de ingreso de agua marina hacia los paisajes mencionados, por ejemplo los cauces activos e inactivos que conectan las lagunas costeras con el mar y con las planicies palustres y las cubetas de decantación fluviales (Torresan et al., 2012; Andréfouët et al., 2015; Li et al., 2015).

En los paisajes geomorfológicos interiores, los procesos de intemperismo y karsificación (Tabla 2 y Figura 2) coinciden con los reportados por Ortiz-Pérez et al. (2005), Geissert-Kientz y Enríquez-Fernández (2011), Pikelj y Juracic (2013) y Zavala-Cruz et al. (2016). Por tener relieves de topografía elevada (mayor a $3 \mathrm{msnm}$ ), como las terrazas onduladas y lomeríos con cimas en cúpulas (Tabla 2 y Figura 3), no serán impactados por elevación del nivel del mar (Ojeda et al., 2009; Rahmstorf, 2012).

\subsection{INDICADORES DE VULNERABILIDAD GEOMORFOLÓGICA EN ZONAS COSTERAS DE TABASCO Y CAMPECHE, MÉXICO}

La cartografía de los paisajes geomorfológicos a nivel de reconocimiento (escala 1:250000) y de los relieve/modelados a nivel semidetallado (escala 1:50000), basados en el enfoque geopedológico, permitió generar indicadores geomorfológicos para evaluar la vulnerabilidad de la costa de Tabasco y Campeche a la inundación ante el ascenso del nivel del mar debido al cambio climático. De acuerdo a incrementos del nivel del mar del orden de $1.7 \pm 0.3 \mathrm{~mm} /$ año (IPGC, 2007), los paisajes geomorfológicos más vulnerables ante el cambio climático serían las planicies costera, baja de inun- dación lagunar y palustre, y dentro de éstas los relieves indicadores son cordones de playa, llanura fluvio-marina, depresión de turba, petenes con turba, llanura salina, delta de marea, dunas costeras y depresión de resurgencias, sumando una superficie de muy alta a muy extrema vulnerabilidad de $9996.7 \mathrm{~km}^{2}$, que representa el $45 \%$ de la zona de estudio, donde el agua podría entrar de 42 a $68 \mathrm{~km}$ tierra adentro (Tabla 2 y Figura 4); esta área es 0.8 a 1.7 veces mayor a la reportada por Flores-Verdugo et al. (2011) y Caetano et al. (2011) para Tabasco y Campeche. En general, concuerda con la zona costera altamente susceptible a ser inundada por los fenómenos extremos que se prevén como consecuencia del cambio climático global, en particular la llanura deltaica del sistema Grijalva-Usumacinta en Tabasco, así como la mayor parte de la zona costera de Campeche (Caetano et al., 2011; Rosete-Vergés et al., 2013), en razón de su topografía plana donde cualquier incremento en el nivel del mar afectaría amplias superficies (Addo, 2013). Zonas costeras con geoformas similares han sido reportadas como vulnerables a inundación por elevación del nivel del mar ante el cambio climático (Ortiz-Pérez et al., 2010; Zavala-Hidalgo et al., 2011; Addo, 2013; French y Burningham, 2013; Andréfouët et al., 2015; Islam et al., 2015).

Entre los relieve/modelados más vulnerables ante la inundación por elevación del nivel del mar, sobresalen las depresiones de turba y los petenes con turba, que cubren el $24 \%$ de la zona costera de Tabasco y Campeche, al formar parte de los paisajes de planicie baja de inundación lagunar y planicie palustre, situadas en zonas circundantes a las lagunas costeras y en conexión o próximas al Golfo de México; típicamente presentan características como forma cóncava, altura cercana al nivel del mar, pendiente menor a $1 \%$ y suelos tipo Histosol con una capa orgánica suave de un metro de espesor sobre sedimentos fluvio marinos, estas condiciones las hacen susceptibles a procesos de salinización y erosión en respuesta a la elevación del nivel del mar (Zavala et al., 2012; Jiménez, 2014; Zavala-Cruz et al., 2016). 
La vulnerabilidad geomorfológica muy alta a muy extrema, coincide con la zona más extensa de humedales de agua dulce de México, donde sobresalen los de tipo costero, ribereño, lacustre y palustre o pantano de agua dulce (Barba-Macías et al., 2006). Estos humedales representan valores ecológicos que contienen las áreas naturales protegidas de la Laguna de Términos, Los Petenes (Caetano et al., 2011; Flores-Verdugo et al., 2011) y Ría Celestún, en Campeche, y los Pantanos de Centla en Tabasco (Tabla 2 y Figura 4), ubicándose entre los ecosistemas costeros y marinos que estarían expuestos a la pérdida de biodiversidad (Andréfouët et al., 2015; Ellison, 2015). Los manglares de la planicie baja de inundación lagunar (Tabla 2 y Figura 4), también sobresalen por la vulnerabilidad muy extrema por incremento del nivel del mar (Ellison, 2015; Islam et al., 2015; Li et al., 2015); actualmente, se reportan como los ecosistemas más impactados de Tabasco y Campeche (Palacio-Aponte, 2001).

La superficie de muy alta a muy extrema vulnerabilidad por elevación del nivel del mar, incluye ciudades portuarias donde viven 437836 habitantes (INEGI, 2010), similar a lo reportado para zonas urbanas costeras de la India (Sheik y Chandrasekar, 2013). Actualmente los asentamientos humanos de San Francisco de Campeche, del Carmen, Champotón y Villahermosa, tienen amplias superficies expuestas a inundaciones con grado medio a alto (Palacio-Aponte et al., 2006; Galindo-Alcántara, 2009; CGASI, 2011; CENECAM, 2013), como consecuencia del desarrollo sobre relieves asociados a las inundaciones, como las planicies fluviales, cauces inactivos, cordones de playa bajos, planicies salinas y valles acumulativos.

Otros estudios concuerdan con la situación vulnerable de la zona costera en estudio ante las inundaciones por fenómenos hidrometeorológicos actuales. La forma plana a cóncava del relieve de la cuenca baja de los ríos Grijalva y Usumacinta tiende a acumular las precipitaciones de agua provenientes de las cuencas altas, lo que contribuye a que las costas de Tabasco y Campeche se ubiquen entre las más susceptibles a las inundaciones (Silva et al., 2011). La aplicación de modelos digitales de elevación, complementados con datos de campo, evidencian algunas zonas expuestas a inundaciones severas, entre las que sobresalen: a) la planicie del Dren Victoria, Río González y Laguna Mecoacán, por incapacidad de los ríos para transitar los sobre flujos de agua hacia el mar (Pedrozo-Acuña et al., 2012a); b) el curso bajo del Río Tonalá, sobre todo por reducción de la capacidad de drenaje del río durante una marejada de tormenta en la boca del río (Pedrozo-Acuña et al., 2012b); c) la planicie fluvial donde se asienta la ciudad de Villahermosa, por precipitación extraordinaria con periodo de retorno de 100 años (Ramos et al., 2009). En esta planicie, la inundación extraordinaria de 2007 exhibió la vulnerabilidad del estado de Tabasco al afectar el $62 \%$ de su territorio, damnificando a 1200000 habitantes y ocasionando pérdidas económicas de distinta magnitud (Ramos et al., 2009; Álvarez-Gordillo y Tuñón-Pablos, 2016).

En este contexto, la posible elevación del nivel del mar, asociada al cambio climático, contribuirá a agravar el problema de las inundaciones en los paisajes geomorfológicos de planicie baja de inundación lagunar, planicie palustre, planicie costera y en las zonas más bajas de la planicie fluviodeltaica de la planicie costera de Tabasco y Campeche. Los posibles impactos ambientales y sociales hacen prever la necesidad de incluir el riesgo en la ordenación ecológica territorial integral de la zona costera, para plantear acciones de adaptación que disminuyan la vulnerabilidad de la población, la infraestructura, las actividades productivas y de los ecosistemas (Rosete-Vergés et al., 2013).

\section{Conclusiones}

La cartografía de los paisajes geomorfológicos y de los relieve/modelados, basada en el enfoque geopedológico, permitió generar información espacial con suficiente detalle de las geoformas indicadoras para evaluar la vulnerabilidad de la costa de Tabasco y Campeche a la inundación ante el ascenso del nivel del mar debido al cambio climá- 
tico. Se zonificaron ocho paisajes geomorfológicos, de los cuales las planicies costera, baja de inundación lagunar y palustre, contienen relieves indicadores de vulnerabilidad ante el posible ascenso del nivel del mar. El $67 \%$ de la superficie en estudio se caracteriza por presentar forma plana a cóncava, procesos de acumulación de sedimentos no consolidados, pendiente menor a $2 \%$, altura dominante menor a 2 msnm, colindancia con el Golfo de México y por ser la zona receptora de agua y sedimentos terrígenos provenientes de la cuenca alta de los ríos Grijalva y Usumacinta.

Las zonas con muy extrema a muy alta vulnerabilidad geomorfológica a la inundación ante el ascenso del nivel del mar corresponden a relieves de cordones de playa, llanura fluvio-marina, llanura salina, depresión de turba, petenes con turba, blanquizal, delta de marea, dunas costeras y depresión de resurgencias, que cubren el $45 \%$ de la costa de Tabasco y Campeche. Varios asentamientos humanos situados en la zona de estudio tienen usos urbanos sobre o en colindancia con estos relieves y sufren inundaciones recurrentes, por lo que el ascenso del nivel del mar contribuirá a agravar el problema. Dentro de las zonas de muy alta a extrema vulnerabilidad ante el ascenso del nivel del mar sobresalen los valores ecológicos contenidos en las reservas de la biósfera Pantanos de Centla, Los Petenes y Ría Celestún, así como el Área de Protección de Flora y Fauna Laguna de Términos, que conforman los humedales más extensos de México.

\section{Referencias}

Addo, K., 2013, Assessing coastal vulnerability index to climate change: the case of Accra - Ghana: Journal of Coastal Research, 65, 1892-1897.

Aguilera, M.M.A., Zárate, L.J., Barrios, R.F., Jiménez H.A., 2004, Carta geológico minera, Frontera E15-5, 1:250000: Pachuca,
Hidalgo, México, Servicio Geológico Mexicano, Coordinación General de Minería y Secretaría de Economía, 1 mapa con texto.

Álvarez-Gordillo, G. del G., Tuñón-Pablos, E., 2016, Vulnerabilidad social de la población desplazada ambiental por las inundaciones de 2007 en Tabasco (México): Cuadernos de geografía, Revista Colombiana de Geografia, 25(1), 123-138.

Andrade, J.B., Lagos, L.M., Arenas, V.F., 2004, Cuantificación de procesos morfogénicos actuales como indicador de la fragilidad de unidades fisiográficas en la costa de la región de O'Higgins: Revista de Geografia Norte Grande, 31, 63-72.

Andréfouët, S., Dutheil, C., Menkes, G.E., Bador, M., Lengaigne, M., 2015, Mass mortality events in atoll lagoons: Environmental control and increased future vulnerability: Global Change Biology, 21(1), 195-205.

Barba-Macías, E., Rangel-Mendoza, J., RamosReyes, R., 2006, Clasificación de los humedales de Tabasco mediante sistemas de información geográfica: Universidad y Ciencia, 22(2) 101-110.

Bautista, F., Frausto, O., Ihl, T., Aguilar, Y., 2015, Actualización del mapa de suelos del estado de Yucatán México: Enfoque geomorfopedológico y WRB: Ecosistemas y Recursos Agropecuarios, 2(6), 303-315.

Bernatchez, P., Fraser, C., Lefaivre, D., Dugas, S., 2011, Integrating anthropogenic factors, geomorphological indicators and local knowledge in the analysis of coastal flooding and erosion hazards: Ocean \& Coastal Management, 54, 621-632.

Bocco, G., Mendoza, M.E., Velázquez, A., Torres A., 1999, La regionalización geomorfológica como una alternativa de regionalización ecológica en México. El caso de Michoacán de Ocampo: Investigaciones Geográficas, 40, 7-22. 
Bocco, G., Mendoza, M.E., A. Priego, A., Burgos, A., 2010, La cartografía de los sistemas naturales como base geográfica para la planeación territorial: México D.F., SEMARNAT, 71 p.

Brammer, H., 2014, Bangladesh's dynamic coastal regions and sea-level rise: Climate Risk Management, 1, 51-62.

Buch, M., Turcios, M., 2003, Vulnerabilidad socioambiental: aplicaciones para Guatemala, Serie de documentos técnicos número 9 (en línea): Guatemala, Universidad Rafael Landivar, Facultad de Ciencias Ambientales y Agrícolas e Instituto de Agricultura, Recursos Naturales y Ambiente, disponible en <http://biblio3.url. edu.gt/IARNA/SERIETECNINCA/9. pdf>, consultado 28 de abril de 2016.

Caetano, E., Innocentini, V., Maga, V., Martins, S., Méndez, B., 2011, Cambio climático y el aumento del nivel del mar, en Botello, A.V., Villanueva-Fragoso, S., Gutiérrez, J., Rojas-Galaviz, J.L., (eds.), Vulnerabilidad de las zonas costeras mexicanas ante el cambio climático (segunda edición): México, Universidad Autónoma MetropolitanaIztapalapa, UNAM-ICMyL, Universidad Autónoma de Campeche, 283-304.

Cardoso, V.E.A., Sánchez, G.E., Rafael, FJ.A., Mata, H.L., 2005, Carta geológico minera, Campeche E15-3, 1:250000: Pachuca, Hidalgo, México, Servicio Geológico Mexicano, Goordinación General de Minería y Secretaría de Economía, 1 mapa con texto.

Centro Estatal de Emergencias de Campeche (CENECAM), 2013, Plan estatal de contingencias para fenómenos hidrometeorológicos 2013: San Francisco de Campeche, México, Gobierno del Estado de Campeche, reporte técnico, $139 \mathrm{p}$.

Comisión Económica para América Latina y el Caribe (CEPAL), 2012, Efectos de cambio climático en las costas de América Latina y el Caribe: Vulnerabilidad y Exposición: Santiago de Chile, 175 p.

Consultoría Gestoría Ambiental y Seguridad Ambiental (CGASI), 2011, Atlas de peligros naturales del municipio de Carmen 2011: Ciudad del Carmen, México, SEDESOL, H. Ayuntamiento de Carmen, reporte técnico, 139 p.

De la Lanza, E.G., Ortiz-Pérez M.A., Carbajal-Pérez J.L., 2013, Diferenciación hidrogeomorfológica de los ambientes costeros del Pacífico, del Golfo de México y del Mar Caribe, Investigaciones Geográficas: Boletín del Instituto de Geografía, Universidad Nacional Autónoma de México, 81, 33-50.

Domínguez, D.M., Zavala, G.J., MartínezZurimendi, P., 2011, Manejo forestal sustentable de los manglares de Tabasco: Villahermosa, Tabasco, México, Secretaría de Recursos Naturales y Protección Ambiental, Colegio de Postgraduados, $137 \mathrm{p}$.

Ellison, J., 2015, Vulnerability assessment of mangroves to climate change and sealevel rise impacts: Wetlands Ecology and Management, 23(2), 115-137.

Farhan, A.R., Lim, S., 2011, Resilience assessment on coastline changes and urban settlements: a case study in Seribu Islands, Indonesia: Ocean \& Coastal Managemen, 54, 391-400.

Flores-Verdugo, F.J., Casasola, P., De la LanzaEspino, G., Agraz-Hernández, G., 2011, El manglar, otros humedales costeros y el cambio climático, en Botello, A.V., Villanueva-Fragoso, S., Gutiérrez, J., RojasGalaviz, J.L., (eds.), Vulnerabilidad de las zonas costeras mexicanas ante el cambio climático (segunda edición): México, Universidad Autónoma MetropolitanaIztapalapa, UNAM-ICMyL, Universidad Autónoma de Campeche, 205-228. 
French, J.R., Burningham, H., 2013, Coasts and climate: Insights from geomorphology: Progress in Physical Geography, 37(4), 550561.

Galindo-Alcántara, A., Ruiz-Acosta., S. del C., Morales-Hernández, A., Gómez-Cordero, G.M., Salcedo-Meza, M.A., Aguilar-Aguilar, M., Valencia-Martínez, J., RodríguezCórdova, M., 2009, Atlas de riesgos del municipio Centro 2009: Villahermosa, México, Ayuntamiento Municipal de Centro y SEDESOL, reporte técnico, 109 p.

Geissert-Kientz, D., Enríquez-Fernández, E., 2011, Geomorfología, en Cruz, A.A., (coord. y ed.), La biodiversidad en Veracruz: estudio de estado: México D.F, México, Comisión Nacional para el Conocimiento y Uso de la Biodiversidad (CONABIO), Gobierno del Estado de Veracruz, Universidad Veracruzana, Instituto de Ecología, A.C., Vol. 1, 53-98 y Apéndice I.1.

Harvey, N., Nicholls, R., 2008, Global sea-level rise and coastal vulnerability: Sustainable Science, 3, 5-7.

Hernández-Santana, J.R., Ortiz-Pérez, M.A., Méndez-Linares, A.P., Gama-Campillo, L., 2008, Morfodinámica de la línea de costa del estado de Tabasco: tendencias desde la segunda mitad del siglo XX hasta el presente: Investigaciones Geográficas, 65, 7-21.

Instituto Nacional de Estadística y Geografía (INEGI), 2010, Censo de población y vivienda (en línea): México, Dirección General de Estadística Sociodemográfica, disponible en <http://www3.inegi.org.mx/ sistemas/widget/default.aspx>, consultado 09 de mayo de 2016.

Intergovernmental Panel on Climate Change (IPCG), 2007, Climate Change 2007: impacts, adaptation and vulnerability (en línea): Cambridge, UK, Parry, M.L., Canziani, O.F., Palutikof, J.P., van der Linden, P.J., Hanson, C.E., (eds.), contribution of working group II to the fourth assessment report of the IPCG, Cambridge University Press, disponible en <https://www.ipcc.ch/ pdf/assessment-report/ar4/wg2/ar4_wg2_ full_report.pdf $>$, consultado 12 de noviembre de 2015.

Intergovernmental Panel on Climate Change (IPCC), 2012, Resumen para responsables de políticas "en el informe especial sobre la gestión de los riesgos de fenómenos meteorológicos extremos y desastres para mejorar la adaptación al cambio climático (en línea): Nueva York, Estados Unidos de América, Field, C.B., Barros, V., Stocker, T.F., Qin, D., Dokken, J., Ebi, K.L., Mastrandrea, M.D., Mach, K.J., Plattner, G.K., Allen, S.K., Tignor, M., Midgley P.M., (eds.), informe especial de los grupos de trabajo I y II del grupo IPCC, Cambridge University Press, Cambridge, Reino Unido y Nueva York, disponible en <https://www.ipcc.ch/ pdf/special-reports/srex/IPCG_SREX_ ES_web.pdf $>$, consultado 12 de noviembre de 2015.

Islam, M.A., Hossain, M.S., Murshed, S., 2015, Assessment of coastal vulnerability due to sea level change at Bhola Island, Bangladesh: Using geospatial techniques: Journal of the Indian Society of Remote Sensing, 43(3), 625-637.

Jiménez, R.R., 2014, Clasificación y caracterización de suelos de Tabasco con base en el enfoque geomorfopedológico: H. Cárdenas, Tabasco, México, Colegio de Postgraduados, Campus Tabasco, tesis de maestría, 143 p.

Kokot, R.R., Chomnalez, F., 2012, Retroceso de la línea de costa en Las Grutas, provincia de Río Negro: Revista Asociación Geológica Argentina, 69, 88-96.

Li, S., Meng, X., Ge, Z., Zhang, L., 2015, Vulnerability assessment of the coastal mangrove ecosystems in Guangxi, China, to sea-level rise: Regional Environmental Change, 15(2), 265-275. 
Liquete, C., Zulian, G., Delgado, I., Stips, A., Maes, J., 2013, Assessment of coastal protection as an ecosystem service in Europe: Ecological Indicators, 30, 205-217.

Magaña, V., Gómez, L., Neri, C., Landa, R., León, G., Ávila, B., 2011, Medidas de adaptación al cambio climático en humedales del Golfo de México: México, INE, SEMARNAT, WB, Gobierno de Japón, UNAM, UAM, CEGAM, S. C. 92 p.

Marcominii, S.C., López, R.A., 2010, Erosión y manejo costero en Las Toninas, Partido de La Costa, provincia de Buenos Aires: Revista Asociación Geológica Argentina, Buenos Aires, 66(4), 490-498.

Miranda, H.A., Escamilla, D.R., Gama, L.J., 2005, Carta geológico minera, Ciudad del Carmen E15-6, 1:250000: Pachuca, Hidalgo, México, Servicio Geológico Mexicano, Coordinación General de Minería y Secretaría de Economía, 1 mapa con texto.

Nicholls, R.J., 2004, Coastal flooding and wetland loss in the $21^{\text {st }}$ century: changes under the SRES climate and socio-economic scenarios: Global Environmental Change, 14, 69-86.

Nicholls, R., 2007, Adaptation options for coastal areas and infrastructure: an analysis for 2030, Technical Report to the UNFCGG, Bonn, Alemania, 35 p.

Nicholls, R.J., Cazenave, A., 2010, Sea-level rise and its impact on coastal zones: Science, $328,1517-1520$.

Ojeda Zújar, J.J., Álvarez Francoso, J.I., Martín Cajaraville, D., Fraile Jurado, P., 2009, El uso de las tecnologías de la información geográfica para el cálculo del índice de vulnerabilidad costera (GVI) ante una potencial subida del nivel del mar en la costa andaluza (España): GeoFocus, 9, 83-100.

Olivo-Garrido, M.L., Sáez-Sáez, V., Martín-Zazo, A., Soto-Olivo, A., 2012, Vulnerabilidad al incremento del nivel del mar: estrategias de adaptación en el área Cabo Codera-Laguna de Tacarigua, estado Miranda, Venezuela: Terra Nueva Etapa, XVIII(43), 45-70.

Ortiz-Pérez, M.A., Siebe, C. y Cram, S., 2005,

Diferenciación ecogeográfica de Tabasco, en Bueno, J., Álvarez F., Santiago S., (eds.), Biodiversidad del Estado de Tabasco: México, CONABIO e Instituto de Biología de la UNAM, 305-322.

Ortiz-Pérez, M.A., De la Lanza-Espino, E.G., 2006, Diferenciación del espacio costero de México: Un inventario regional: México, Instituto de Geografía, Universidad Nacional Autónoma de México, 138 p.

Ortiz-Pérez, M.A., Sommer-Cervantes, I., Oropeza-Orozco, O., 2010, Criterios para estimar la vulnerabilidad física de las costas de barrera ante los impactos hidrometeorológicos, en Rivera-Arriaga, E., Azuz-Adeath, I., Alpuche-Gual, L., Villalobos-Zapata, G.J., (eds.), Cambio climático en México un enfoque costeromarino, Universidad Autónoma de Campeche CETYS-Universidad, Gobierno del Estado de Campeche, 101-119.

Ortiz-Pérez, M.A., Hernández-Santana, J.R., Figueroa-Mah E., J.M., Gama-Campillo, L.M., 2011, Tasas del avance transgresivo y regresivo en el frente deltaico tabasqueño: en el periodo comprendido del año 1995 al 2008, en Botello, A.V., Villanueva-Fragoso, S., Gutiérrez, J., Rojas-Galaviz, J.L., (eds.), Vulnerabilidad de las zonas costeras mexicanas ante el cambio climático: México, Universidad Autónoma MetropolitanaIztapalapa, UNAM-ICMyL, Universidad Autónoma de Campeche, 393-412.

Palacio-Aponte, G., 2001, Detección de cambios en la morfología litoral de Punta Zacatal y parte occidental de Isla del Carmen, Campeche, mediante el análisis multitemporal de imágenes de satélite: Investigaciones Geográficas, 46, 7-14. 
Palacio-Aponte, A.G., Medina-Medina, V., Bautista, F., 2005, Diagnóstico ambiental de la costa del estado de Campeche: Enfoques geomorfológico y geopedológico, en Bautista-Zúñiga, F., Palacio, A.G. (eds.), Caracterización y manejo de los suelos de la Península de Yucatán: implicaciones agropecuarias, forestales y ambientales, México D.F., Universidad Autónoma de Campeche, Universidad Autónoma de Yucatán, Instituto Nacional de Ecología, 59-72.

Palacio-Aponte, G., Silva-Casarín, R., BautistaGodínez, E.G., Posada-Vanegas, G., RuizMartínez, G., 2006, Atlas de peligros naturales de la ciudad de Campeche, San Francisco de Campeche, México, SEDESOL, H. Ayuntamiento de Campeche, reporte técnico, $96 \mathrm{p}$.

Palacio-Aponte, G., 2010, La morfología costera posthuracán como indicador de la intensidad de la amenaza por huracanes: Interciencia, 35(6), 400-406.

Palma-López, D.J., Zavala, C.J., Bautista, Z.F., Morales, G.M.A., López, C. A., Shirma, T.E.D., Gallegos, T.J.L., 2012, Estudio sobre el plan de uso sustentable de los suelos del estado de Campeche: San Francisco de Campeche, Campeche, México, Colegio de Postgraduados-Secretaria de Desarrollo Rural de Campeche, reporte técnico, 141 p.

Pedrozo-Acuña, A., Mariño-Tapia, I., Enriquez, C., Medellín-Mayoral, G., GonzálezVillareal, F.J., 2012a, Evaluation of inundation areas resulting from the diversion of an extreme discharge towards the sea: case study in Tabasco, Mexico: Hydrological Processes, 26, 687-704.

Pedrozo-Acuña, A., Ruiz de Alegria-Arzaburu, A., Mariño-Tapia, I., Enriquez, C., GonzálezVillareal, F.J., 2012b, Factors controlling flooding at the Tonalá river mouth (Mexico): Journal of Flood Risk Management, 5, 226244.
Pikelj, K., Juracic, M., 2013, Eastern Adriatic coast (EAC): geomorphology and coastal vulnerability of a karstic coast: Journal of Coastal Research, 29(4), 944-957.

Rahmstorf, S., 2012, Sea-level rise: towards understanding local vulnerability: Environmental Research Letters, 7, 1-3.

Ramos, J., Marrufo L., González, F.J., 2009, Use of Lidar data in floodplain risk management planning: the experience of Tabasco 2007 flood, en Jedlovec, G., (ed.), Advances in Geoscience and Remote Sensing, INTECH, Rijeka, 659-678.

Rosete-Vergés, F.A., Enríquez-Hernández, G., Aguirre-von Wobeser, E., 2013, El componente del riesgo en el ordenamiento ecológico del territorio: el caso del ordenamiento ecológico regional y marino del Golfo de México y Mar Caribe: Investigaciones Geográficas, 80, 7-20.

Sheik, M.P., Chandrasekar, N., 2013, Coastal erosion hazard and vulnerability assessment for southern coastal Tamil Nadu of India by using remote sensing and GIS: Natural Hazards, 69(3), 1295-1314.

Silva, I.H.C., Miranda, F.P., Beisl, G.H., Landaus, L., 2011, System for flooding alert in tropical coastal zones using GIS and remote sensing: a case study in Villahermosa, México: Journal of Coastal Research, 57, 1736-1739.

Thieler, R., Hammer, E., 1999, National assessment of coastal vulnerability to sealevel rise: preliminary results for the U.S. Atlantic coast. U.S: Geological Survey. Woods Hole, Massachusetts, 99-593.

Torres-Rodríguez, V., Márquez-García, A., Bolongaro-Crevenna, A., ChavarriaHernández, J., Expósito-Díaz, G., Márquez-García, E., 201 1, Tasa de erosión y vulnerabilidad costera en el estado de Campeche debido a efectos del cambio climático, en Botello, A.V., VillanuevaFragoso, S., Gutiérrez, J., Rojas-Galaviz, J.L., (eds.), Vulnerabilidad de las zonas 
costeras mexicanas ante el cambio climático: México, Universidad Autónoma Metropolitana-Iztapalapa, UNAM-ICMyL, Universidad Autónoma de Campeche, 413432.

Torresan, S., Critto, A., Rizzi, J., Marcomini, A., 2012, Assessment of coastal vulnerability to climate change hazards at the regional scale: the case study of the north Adriatic Sea: Natural Hazards and Earth System Sciences, 12(7), 2347-2368.

Zavala, G.J., Palma-López, D.J., Morales, G.M.A., 2012, Clasificación de suelos de la cuenca baja del Río Tonalá, Tabasco, en Zavala, G.J., García, L.E., (eds.), Suelo y vegetación de la cuenca baja del río Tonalá, Tabasco: H. Cárdenas, Tabasco, México, Colegio de Posgraduados, 31-58.

Zavala-Cruz, J., Jiménez-Ramírez, R., PalmaLópez, D.J., Bautista-Zúñiga, F., GaviReyes, F., 2016, Paisajes geomorfológicos: base para el levantamiento de suelos en Tabasco, México: Ecosistemas y Recursos Agropecuarios, 3(8) 161-171.
Zavala-Hidalgo, J., De Buen-Kalman, R., Romero-Genteno, R., Hernández-Maguey, F., 2011, Tendencias del nivel del mar en las costas mexicanas, en Botello, A.V., Villanueva-Fragoso, S., Gutiérrez, J., RojasGalaviz, J.L., (eds.), Vulnerabilidad de las zonas costeras mexicanas ante el cambio climático (segunda edición): México, Universidad Autónoma MetropolitanaIztapalapa, UNAM-ICMyL, Universidad Autónoma de Campeche, 315-334.

Zhang, K., Douglas, B.C., Leatherman, S.P., 2004, Global warming and coastal erosion: Climate Change, 64, 41-58.

Zinck, A.J., 2012, Geopedología: elementos de geomorfología para estudios de suelos y de riesgo naturales, Faculty of Geo-Information Science and Earth Observation, Enschede, The Netherlands, 123 p. 